\title{
Effects of Insulin Infusion on Human Skeletal Muscle Pyruvate Dehydrogenase, Phosphofructokinase, and Glycogen Synthase

\author{
Evidence for Their Role in Oxidative and Nonoxidative Glucose Metabolism
}

\author{
Lawrence J. Mandarino, Kimberly S. Wright, Larry S. Verity, Jeanne Nichols, Jo Marie Bell, \\ Orville G. Kolterman, and Henning Beck-Nielsen \\ Department of Medicine and General Clinical Research Center, University of California, San Diego, and Department of Physical \\ Education, San Diego State University, San Diego, California 92103
}

\begin{abstract}
To determine whether activation by insulin of glycogen synthase (GS), phosphofructokinase (PFK), or pyruvate dehydrogenase (PDH) in skeletal muscle regulates intracellular glucose metabolism, subjects were studied basally and during euglycemic insulin infusions of 12,30 , and $240 \mathrm{mU} / \mathrm{m}^{2} \cdot \mathrm{min}$. Glucose disposal, oxidative and nonoxidative glucose metabolism were determined. GS, PFK, and PDH were assayed in skeletal muscle under each condition. Glucose disposal rates were $2.37 \pm 0.11,3.15 \pm 0.19,6.71 \pm 0.44$, and $11.7 \pm 1.73$ $\mathrm{mg} / \mathrm{kg} \cdot \mathrm{min}$; glucose oxidation rates were $1.96 \pm 0.18$, $2.81 \pm 0.28,4.43 \pm 0.32$, and $5.22 \pm 0.52$. Nonoxidative glucose metabolism was $0.39 \pm 0.13,0.34 \pm 0.26,2.28 \pm 0.40$, and $6.52 \pm 1.21 \mathrm{mg} / \mathrm{kg} \cdot \mathrm{min}$. Both the proportion of active GS and the proportion of active $\mathrm{PDH}$ were increased by hyperinsulinemia. PFK activity was unaffected. Activation of GS was correlated with nonoxidative glucose metabolism, while activation of PDH was correlated with glucose oxidation. Sensitivity to insulin of GS was similar to that of nonoxidative glucose metabolism, while the sensitivity to insulin of PDH was similar to that of glucose oxidation. Therefore, the activation of these enzymes in muscle may regulate nonoxidative and oxidative glucose metabolism.
\end{abstract}

\section{Introduction}

The initial event in the cascade of insulin action is the binding of insulin to its cell-surface receptor. After this, a series of steps lead to the manifold actions of insulin. These steps are poorly understood at the present time. In tissues such as fat and muscle, insulin increases glucose transport into the cell via a specific transport system and activates enzymes responsible for metabolizing glucose. In human subjects, creation of hyperinsulinemia while maintaining constant glycemia results in increased rates of disappearance of glucose from the circulation. Under these conditions, the majority of glucose disappearance is accounted for by skeletal muscle (1). Despite the quantitative importance of skeletal muscle in overall insulin-stimu-

Address reprint requests to Dr. Mandarino, The Eye and Ear Institute of Pittsburgh, University of Pittsburgh, 203 Lothrop Street, Pittsburgh, PA 15213. Dr. Beck-Nielsen's current address is Hvidore Hospital, Klampenborg, Denmark 2920.

Received for publication 9 January 1987 and in revised form 6 April 1987.

J. Clin. Invest.

(c) The American Society for Clinical Investigation, Inc.

0021-9738/87/09/0655/09 \$2.00

Volume 80, September 1987, 655-663 lated glucose metabolism, relatively few investigations have assessed the mechanisms and pathways of insulin-mediated glucose metabolism in this tissue in man.

Once glucose enters the muscle cell, it is phosphorylated to form glucose 6-phosphate (G6P) ${ }^{1}$ and routed into one of two major pathways, glycogen synthesis or glycolysis. In turn, glycolysis leads either to production of pyruvate that is either converted to lactate or enters the Krebs cycle for further oxidation. Alternatively, storage of glucose as glycogen is the predominant route of nonoxidative glucose metabolism under conditions of insulin stimulation $(2,3)$, and its rate appears to be regulated by the enzyme glycogen synthase (3). In muscle, glycogen synthase (GS) is activated by its allosteric effector G6P $(4,5)$ and in human muscle is dephosphorylated and activated by insulin infusion (6-9). Activation of muscle GS by insulin in man has been correlated with the activation of nonoxidative glucose metabolism by insulin in studies in which nonoxidative glucose metabolism was defined as the difference between isotopically determined overall glucose disposal and overall glucose oxidation determined by indirect calorimetry (3).

Glycolysis is also regulated in part by phosphofructokinase (PFK). Regulation of PFK occurs primarily by changes in the concentration of citrate, its negative allosteric effector (10). Increased citrate concentration can result from increased fatty acid oxidation, and inhibition of PFK and glycolysis in this manner forms part of the basis of the Randle glucose fatty acid fuel homeostasis hypothesis (10-13). Oxidation of pyruvate derived from glycolysis, in turn, is regulated by the enzyme pyruvate dehydrogenase (PDH). While overall glucose oxidation is activated by insulin (2), the effect of insulin on PDH in human skeletal muscle has not been investigated. In fat cells from rats (14) and humans (15), insulin activates PDH by increasing the proportion of PDH which is present in its active, dephosphorylated state. This effect of insulin is presumed to be mediated by an increase in the activity of PDH phosphatase, which is present in the PDH multienzyme complex $(16,17)$. Among the known inhibitors of PDH are acetyl CoA and NADH, which are also products of fatty acid oxidation (16, 17). Thus, inhibition of PDH by fat oxidation products also plays a role in the Randle hypothesis (10-13).

Insulin resistance reflected by reduced insulin-stimulated glucose disposal rates in vivo is a prominent feature of obesity and noninsulin-dependent diabetes mellitus (NIDDM). Some

1. Abbreviations used in this paper: DTT, dithiothreitol; F6P, fructose 6-phosphate; G6P, glucose 6-phosphate; GS, glycogen synthase; NIDDM, noninsulin-dependent diabetes mellitus; $P D H$, pyruvate dehydrogenase; $\mathrm{PDH}_{\mathrm{a}}$, active $\mathrm{PDH} ; \mathrm{PDH}_{\mathrm{t}}$, total PDH; PFK, phosphofructokinase; RER, respiratory exchange ratio. 
of this insulin resistance may be due to a decrease in insulin receptor binding to target tissues $(18,19)$, although this remains controversial (20-22). The majority of insulin resistance appears to be due to postbinding defects (18), which cannot be wholly accounted for by a defect in the glucose transport system (23). These intracellular abnormalities in the effects of insulin on glucose metabolism are poorly defined. In this regard, decreased insulin-stimulated rates of both oxidative and nonoxidative glucose metabolism have been reported in obese and NIDDM subjects (24). This suggests that in these diseases there may be abnormalities in intracellular insulinsensitive regulatory steps for glucose metabolism. Since GS, PFK, and PDH in skeletal muscle are potential regulators of insulin-stimulated nonoxidative and oxidative metabolism of glucose in man, the present studies were undertaken to determine the relationships between the activation of whole-body oxidative and nonoxidative glucose metabolism by insulin with the effects of insulin on PDH, PFK, and GS activity in skeletal muscle biopsies from normal subjects. These studies should serve as a framework for the study of intracellular insulin-stimulated glucose metabolism in human muscle so that the defects in muscle glucose metabolism in obesity and NIDDM can be identified.

\section{Methods}

All studies were approved by the Committee on Investigations Involving Human Subjects, University of California, San Diego. Informed, written consent was obtained from each subject before study. All subjects had normal glucose tolerance (25). Characteristics of the subjects are shown in Table I.

\section{In vivo methods}

Study design. The design of the studies is outlined in Fig. 1. Subjects ( $n$ $=8$ ) were admitted to the General Clinical Research Center, University of California, San Diego, on the evening before the study. Euglycemic insulin infusions were performed following an overnight fast as previously described (19). After a 90 -min period for equilibration of plasma $\left[3-{ }^{3} \mathrm{H}\right]$ glucose, basal glucose disposal rates were measured for an additional $30 \mathrm{~min}$. During the last $40 \mathrm{~min}$ of this period, gas exchange rates were measured for determination of respiratory exchange ratio (RER). A needle biopsy of the vastus lateralis muscle was then performed under local anesthesia, requiring less than $20 \mathrm{~min}$ from start to finish. A primed, continuous infusion of insulin was then started

Table I. Subject Characteristics

\begin{tabular}{llllll}
\hline Subject & Age & Sex & BMI & Serum insulin & FFA \\
\hline & $y r$ & & $k g / M^{2}$ & $\mu U / m l$ & $m M$ \\
1 & 22 & M & 20 & 5 & 0.314 \\
$2^{*}$ & 24 & M & 25 & 7 & 0.860 \\
3 & 31 & M & 27 & 7 & 0.259 \\
$4^{*}$ & 39 & M & 31 & 7 & 0.564 \\
$5^{*}$ & 25 & M & 32 & 6 & 0.641 \\
$6^{*}$ & 23 & M & 26 & 12 & 0.327 \\
7 & 22 & F & 23 & 6 & 0.640 \\
$8^{*}$ & 22 & F & 20 & 6 & 0.228 \\
Mean & 26 & $6 M / 2 F$ & 25.5 & 7 & 0.479 \\
SEM & 2 & & 1.6 & 1 & 0.081 \\
& & & & & \\
\hline
\end{tabular}

* Subjects who received $240 \mathrm{mU} / \mathrm{m}^{2} \cdot \min$ insulin infusion.

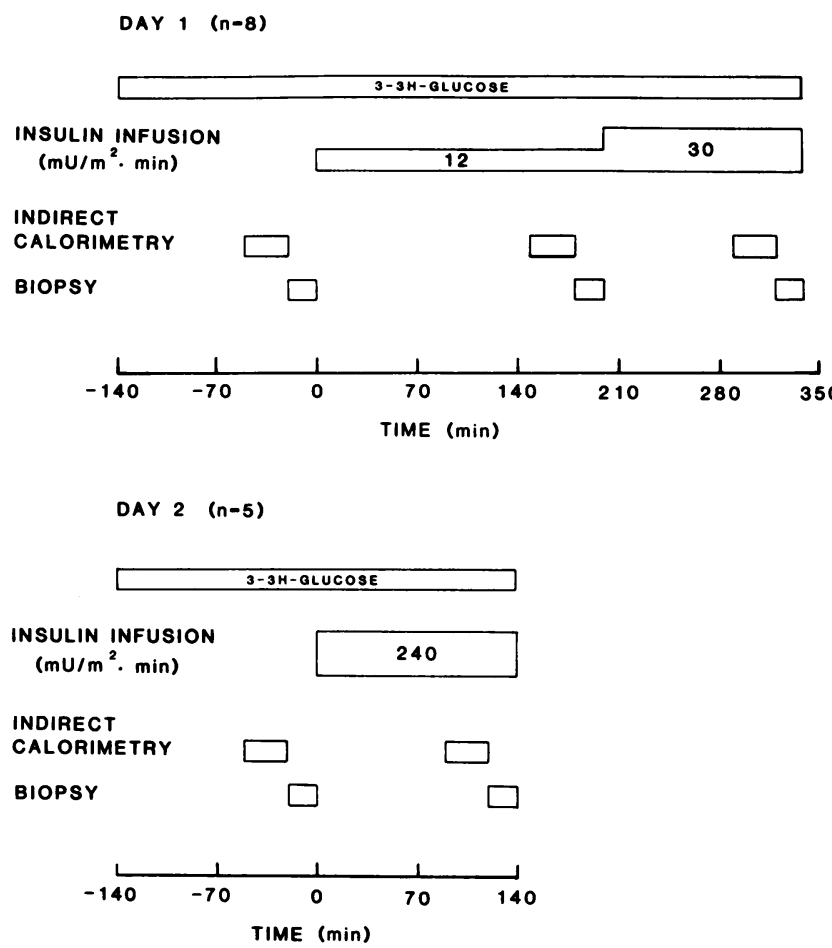

Figure 1. Outline of the studies. Eight subjects were studied on day 1. Five of these subjects were also studied at the $240-\mathrm{mU} / \mathrm{m}^{2} \cdot \mathrm{min}$ insulin infusion on day 2 (see Table I for identification). Indirect calorimetry was performed continuously during the indicated periods.

and continued at a rate of $12 \mathrm{mU} / \mathrm{m}^{2} \cdot \min$ for $180 \mathrm{~min}$. Glucose disposal rates were determined during the last $30 \mathrm{~min}$ of this interval of measurement of RER was performed during the last $\mathbf{4 0} \mathrm{min}$. After this, another muscle biopsy was performed in the same leg at a site $\sim 2 \mathrm{~cm}$ distal to the first biopsy. Upon completion of that biopsy, the insulin infusion rate was increased to $30 \mathrm{mU} / \mathrm{m}^{2} \cdot \min$ for an additional 120 min. Glucose disposal rates and RER were determined as described above, and a third muscle biopsy was performed in the same leg. During the periods of insulin infusion, plasma glucose was maintained at $90 \pm 5 \mathrm{mg} / \mathrm{dl}$ by a variable infusion of $20 \%$ glucose.

On a separate occasion, five of the eight subjects (see Table I) were again admitted to the Clinical Research Center on the evening prior to study. The following morning, another determination of basal glucose disposal and RER was made as described above, and a muscle biopsy was performed. Insulin was then infused at a rate of $240 \mathrm{mU} / \mathrm{m}^{2} \cdot \min$ for $120 \mathrm{~min}$. Glucose disposal rates and RER were measured and another muscle biopsy performed.

$R E R$. RER was determined as 1-min averages from continuous breath collection by means of an indirect calorimeter (Alpha Technologies MTS 4400, Sensormedics, Inc., Anaheim, CA). The system was equipped with a facemask, which was well tolerated by all subjects. Minute averages of $\mathrm{O}_{2}$ consumption and $\mathrm{CO}_{2}$ production were used to calculate glucose and fat oxidation rates by the equations of Frayn (26). At the higher insulin infusion rate, the RER sometimes slightly exceeded 1.0, which results in negative net fat oxidation rates. Glucose oxidation rates may, therefore, include a small component of lipogenesis. Rates of nonoxidative glucose metabolism were estimated by subtracting the rates of glucose oxidation from overall glucose disposal rates. It should be stressed that such estimates represent net processes and should be viewed as semiquantitative.

Glucose disposal rates. Glucose disposal rates were determined isotopically using a primed $(60 \mu \mathrm{Ci})$, continuous $(0.6 \mu \mathrm{Ci} / \mathrm{min})$ infusion of $\left[3-{ }^{3} \mathrm{H}\right]$ glucose (New England Nuclear, Boston, MA). Blood samples were obtained at 20-min intervals for the measurement of 
serum glucose and glucose specific activities. Glucose disposal rates during the basal period and the 12 - and $30-\mathrm{mU} / \mathrm{m}^{2} \cdot \mathrm{min}$ insulin infusions were calculated from glucose specific activities by the equations of Steele (27). Since at very high insulin concentrations these equations underestimate the glucose disposal rate, during the $240-\mathrm{mU} / \mathrm{m}^{2} \cdot \mathrm{min}$ insulin infusion, the infusion rate of exogenous glucose required to maintain euglycemia was assumed to be equal to the glucose disposal rate during the $240 \mathrm{mU} / \mathrm{m}^{2} \cdot \min$ infusion.

Muscle biopsy. Muscle biopsies were performed with Bergstrom needles (28). After xylocaine anesthesia of the skin and subcutaneous tissue down to the muscle sheath, a small incision was made through the skin and into the muscle fasciae. The biopsy needle was passed through this incision into the muscle. $50-150 \mathrm{mg}$ of muscle was obtained and frozen in liquid nitrogen within $\sim 15 \mathrm{~s}$.

\section{In vitro techniques}

Muscle extraction. Extraction of muscle for enzyme assays was done by a modification of the method of Hagg et al. (29). Muscle samples were weighed while still frozen and immediately homogenized in an ice-cold buffer consisting of $2.0 \mathrm{mM}$ dithiothreitol (DTT), $20 \mathrm{mM}$ sodium fluoride, $20 \mathrm{mM}$ EDTA, and $50 \mathrm{mM}$ potassium phosphate, $\mathrm{pH} \mathrm{7.4,} 50$ $\mathrm{mg}$ tissue/ml buffer. Fluoride was included to inhibit PDH phosphatase (17) in order to maintain PDH in its in situ phosphorylation state. Homogenization was accomplished by 10 passes with a polytron homogenizer (Brinkmann Instruments, Westbury, NY) on setting 5, followed by $5 \mathrm{~s}$ of continual homogenization on setting 7 . This and all subsequent steps were carried out at $4^{\circ} \mathrm{C}$. The crude extract was then centrifuged at $20,000 \mathrm{~g}$ for $20 \mathrm{~min}$ in an ultracentrifuge (L5-50, Beckman Instruments, Inc., Fullerton, CA). The supernatant contained essentially all GS and PFK activity and was saved on ice for this purpose. The pellet, which contained nearly all (>95\%) of the PDH activity, was divided into two portions. One portion of the pellet was resuspended in the same homogenization buffer for assay of active PDH (termed $\mathrm{PDH}_{\mathrm{a}}$ ), and the other portion was resuspended in the homogenization buffer without sodium fluoride for assay of total $\mathrm{PDH}$, termed $\mathrm{PDH}_{\mathrm{t}}$ (see below). Removal of fluoride allowed activation of PDH by high magnesium concentrations, presumably through activation of PDH phosphatase.

These suspensions were recentrifuged as above and the supernatant was discarded. The pellets were homogenized with five passes of a polytron (setting 4-5) on ice in buffer identical to the previous buffers except with the addition of $0.2 \%$ Triton X-100 to solubilize mitochondrial membranes to allow free access of substrates to the enzyme. The pellet to be used for determination of total PDH $\left(\mathrm{PDH}_{\mathrm{t}}\right)$ activity was resuspended in buffer containing $0.2 \%$ Triton $\mathrm{X}-100$ but no fluoride. Protein content of these extracts was determined by the method of Lowry (30).

$P D H$ assay. The rationale behind the $\mathrm{PDH}$ assay depends upon the following assumptions. PDH exists in dephospho- (more active) and phospho- (less active) forms. PDH activity in muscle extracts can be determined at low $(50 \mu \mathrm{M})$ concentrations of $\mathrm{Mg}^{+2}$ and $\mathrm{Ca}^{+2}$ in the presence of fluoride to inhibit PDH phosphatase. This activity can be termed "active" PDH, or $\mathrm{PDH}_{\mathrm{a}}$, and is thought to be a measure of that portion of $\mathrm{PDH}$ that is active in vivo. $\mathrm{PDH}_{\mathrm{t}}$ can be determined by incubation of enzyme with $0.5 \mathrm{mM} \mathrm{Ca}^{+2}$ and $20 \mathrm{mM} \mathrm{Mg}^{+2}$ in order to fully activate PDH phosphatase and thus fully dephosphorylate and activate $\mathrm{PDH}$. $\mathrm{PDH}_{\mathrm{t}}$ is thought to represent the total $\mathrm{PDH}$ activity present. The ratio $\mathrm{PDH}_{\mathrm{a}} / \mathrm{PDH}_{\mathrm{t}}$ has been used as a measure of the extent of activation of PDH in vivo.

PDH assays were performed by a modification of the method of Hagg et al. (29), based on the technique of Blass et al. (31). To carry out these assays, muscle extract pellets prepared as described above were preincubated for $15 \mathrm{~min}$ at $37^{\circ} \mathrm{C}$ in either of two solutions. In one, for determination of $\mathrm{PDH}_{\mathrm{a}}$ activity, solubilized pellets $(75 \mu \mathrm{l})$ prepared with fluoride present were preincubated with $25 \mu$ l of a solution consisting of final concentrations of $50 \mu \mathrm{M} \mathrm{Ca}^{+2}, 50 \mu \mathrm{M} \mathrm{Mg}^{+2}, 2.0 \mathrm{mM}$ DTT, and $50 \mathrm{mM}$ potassium phosphate, $\mathrm{pH}$ 7.4. In the other, for determination of $\mathrm{PDH}_{\mathrm{t}}$ activity, solubilized pellets $(75 \mu \mathrm{l})$ were prein- cubated with $25 \mu \mathrm{l}$ of a solution consisting of $0.5 \mathrm{mM} \mathrm{Ca}^{+2}, 20 \mathrm{mM}$ $\mathrm{mg}^{+2}, 2.0 \mathrm{mM}$ DTT, and $50 \mathrm{mM}$ potassium phosphate, $\mathrm{pH}$ 7.4. These preincubations were carried out in $15 \times 100$-mm polyethylene tubes. After these preincubations, the reactions were started by addition of 25 $\mu \mathrm{l}$ of a mixture of substrates and cofactors such that final concentrations were as follows: $\beta$-nicotinamide adenine dinucleotide, $5.0 \mathrm{mM}$; coenzyme A, $1.0 \mathrm{mM}$; thiamine pyrophosphate, $1.0 \mathrm{mM}$; DTT, 2.0 $\mathrm{mM} ;\left[1-{ }^{14} \mathrm{C}\right]$ pyruvic acid $(0.2 \mu \mathrm{Ci}$, New England Nuclear); unlabeled pyruvic acid, $0.05-4.3 \mathrm{mM}$; and $50 \mathrm{mM}$ potassium phosphate, $\mathrm{pH}$ 7.4. The tubes were immediately capped with a rubber stopper through which was suspended a plastic well containing a small roll of filter paper. After $20 \mathrm{~min}$, the reactions were stopped by injecting $0.2 \mathrm{ml}$ of 6 $\mathrm{N} \mathrm{H}_{2} \mathrm{SO}_{4}$ through the rubber stopper into the reaction mixture. ${ }^{14} \mathrm{CO}_{2}$ was collected for $30 \mathrm{~min}$ by injecting $0.2 \mathrm{ml} \mathrm{N}$ Hyamine hydroxide through the rubber stopper onto the filter paper in the center well. The filters were counted in OCS (organic counting scintillant, Amersham Corporation, Arlington Heights, IL), and all counts were corrected for quenching. Blank values were determined by using boiled tissue extracts under the same assay conditions as above. Such blanks have values of about $20 \%$ of other assay values but vary depending on the pyruvate specific activity. Maintenance of low blank values is dependent upon proper storage of $\left[1-{ }^{14} \mathrm{C}\right]$ pyruvic acid. This material, when stored in $0.04 \mathrm{~N} \mathrm{HCl}$ at $4^{\circ} \mathrm{C}$, is stable for $2-3 \mathrm{mo}$. At neutral $\mathrm{pH}$, however, spontaneous decarboxylation resulting in high blank values occurs even when pyruvic acid is stored at $-70^{\circ} \mathrm{C}$. Blank values were subtracted from all other values, and results were expressed as picomoles of pyruvate oxidized per minute per milligram extract protein. A range of pyruvate concentrations was used to allow calculation of $V_{\max }$ (maximal reaction rate) and $K_{\mathrm{m}}$ (Michaelis constant) for pyruvate.

GS assay. Glycogen synthase was assayed by a modification of the method of Thomas et al. (32). The initial supernatant from the first centrifugation step which contains nearly $100 \%$ of GS activity present in the crude extract following muscle homogenization was diluted 1:5 in a buffer consisting of $20 \mathrm{mM}$ EDTA, $25 \mathrm{mM}$ sodium fluoride, and $50 \mathrm{mM}$ Tris- $\mathrm{HCl}, \mathrm{pH}$ 7.8. Reactions were started by addition of $30-\mu \mathrm{l}$ aliquots of cell extracts to $60 \mu \mathrm{l}$ of a reaction mixture composed of 20 mM EDTA, $25 \mathrm{mM}$ sodium fluoride, $50 \mathrm{mM}$ Tris- $\mathrm{HCl}$ (pH 7.8), 1\% glycogen, $0.7 \mu \mathrm{Ci} \mathrm{U}-\left[{ }^{14} \mathrm{C}\right]$ uridine diphosphate glucose (UDPG), 0.3 mM UDPG, and 0-10 mM G6P. Maximal GS activity was determined at saturating concentrations of G6P $(10 \mathrm{mM})$ and UDPG $(5 \mathrm{mM})$. Reactions were allowed to proceed for $15 \mathrm{~min}$ at $30^{\circ} \mathrm{C}$ and were terminated by precipitating 75- $\mu$ l aliquots of the reaction mixture on $2 \times 2$ $\mathrm{cm}$ squares of filter paper immediately dropped into cold $66 \%$ ethanol. After $30 \mathrm{~min}$ of washing, the filter papers were washed twice for $20 \mathrm{~min}$ each in cold $66 \%$ ethanol, once for $5 \mathrm{~min}$ in acetone, dried, and placed in OCS for determination of radioactivity. Enzyme activity was expressed as nanomoles of UDPG incorporated into glycogen per minute per milligram extract protein.

Performing the assay with a range of $\mathrm{G} 6 \mathrm{P}$ concentrations was done to allow determination of the Hill coefficient and an $A_{0.5}$ for G6P as well as calculation of activity ratios or fractional velocities that are thought to reflect the proportion of total GS present that is active at various G6P concentrations. The $A_{0.5}$ of GS for G6P has been found to be a sensitive measurement of changes in GS activity in experimental diabetes, fasting, and exercise (33-35).

PFK assay. PFK was assayed in supernatants of muscle extracts by a modification of the method of Beutler (36). The same initial supernatant employed in the GS assay was used for the PFK assay except without dilution. The assay coupled the conversion of fructose 6phosphate (F6P) to fructose 1,6-diphosphate with the oxidation of NADH by means of a series of enzymatic steps including aldolase, triose phosphate isomerase, and $\alpha$-glycerophosphate dehydrogenase. These three enzymes ("auxiliary" enzymes) were added to the reaction. The reaction constituents were ATP, $2 \mathrm{mM} ; \mathrm{MgCl}_{2}, 5 \mathrm{mM}$; NADH, $0.2 \mathrm{mM}$; F6P, 0.3-2 mM, $30 \mu \mathrm{l}$ muscle extract, and the auxiliary enzymes ( $5 \mathrm{U}$ each) in $50 \mathrm{mM}$ Tris buffer, $\mathrm{pH} \mathrm{8.0.} \mathrm{Total} \mathrm{assay}$ volume was $1.0 \mathrm{ml}$. Disappearance of $\mathrm{NADH}$ was monitored at $340 \mathrm{~nm}$ 
Analytical techniques. Blood for serum insulin was collected in siliconized tubes. Blood for glucose specific activity was collected in tubes containing sodium fluoride, while blood for FFA determinations was collected in EDTA tubes. Plasma glucose was determined with a glucose analyzer (Yellow Springs Instruments, Yellow Springs, $\mathrm{OH}$ ). Tritium counts in glucose were determined on perchloric acid extracts of plasma. Insulin was assayed by double-antibody radioimmunoassay. Free fatty acids in plasma were determined by the method of Itaya et al. (37), and lactate by the method of Passonneau (38).

Calculations and statistical methods. The Hill coefficient $(n)$ and the $A_{0.5}$ and $V_{\max }$ was determined by fitting data to the Hill equation, $v$ $-v_{0}=\left(V_{\max } \mathrm{G} 6 \mathrm{P}-v_{0}\right)\left([A]^{n}\right) /\left([A]+\left[A_{0.5}\right]^{n}\right)$ where $\mathrm{v}$ is the measured velocity of the GS reaction in the presence of subsaturating concentrations $[A]$ of $\mathrm{G} 6 \mathrm{P} ; v_{0}$ is the measured velocity of the enzyme in the absence of G6P; $V_{\max } \mathrm{G} 6 \mathrm{P}$ is the estimated enzyme velocity at infinite G6P concentration; $A_{0.5}$ is the concentration of G6P required for halfmaximal activity and $n$ is the Hill coefficient (33). Parameters were estimated by means of a least squares algorithm. For PDH and PFK, the $K_{\mathrm{m}}$ and $V_{\max }$ for pyruvate were determined by fitting enzyme activity data to the Michaelis-Menten equation.

Comparisons between groups were made with repeated measures analysis of variance where appropriate (39). Where F-ratios were significant, further comparisons were made using $a$ posteriori $t$ tests.

\section{Results}

In vivo glucose metabolism. The relationships between plasma insulin concentration and rates of overall glucose disposal, oxidative metabolism of glucose, and nonoxidative metabolism of glucose, are shown in Fig. 2 and Table II. Serum insulin concentrations were $7 \pm 1,22 \pm 2,49 \pm 3$, and $631 \pm 49 \mu \mathrm{U} / \mathrm{ml}$ during the basal period and the $12-, 30-$, and $240-\mathrm{mU} / \mathrm{m}^{2} \cdot \mathrm{min}$ insulin infusions, respectively. Glucose disposal and oxidation were significantly activated during the 12,30 , and 240 $\mathrm{mU} / \mathrm{m}^{2} \cdot \mathrm{min}$ insulin infusion $(P<0.01)$. Nonoxidative glucose metabolism, however, was not increased at the $12-\mathrm{mU} /$ $\mathrm{m}^{2} \cdot \mathrm{min}$ infusion, but was activated during the 30 and 240 $\mathrm{mU} / \mathrm{m}^{2} \cdot \mathrm{min}$ infusion. From the individual values for glucose disposal and oxidation, it could be calculated that glucose oxidation represented $82 \pm 6 \%$ of overall glucose disposal in the basal state and $90 \pm 8,67 \pm 4$, and $44 \pm 6 \%$ during the 12-, 30-, and $240-\mathrm{mU} / \mathrm{m}^{2} \cdot \mathrm{min}$ infusions, respectively. Plasma lactate concentration was $0.95 \pm 0.09 \mathrm{mM}$ basally and $0.81 \pm 0.05$, $1.08 \pm 0.11$, and $1.75 \pm 0.23 \mathrm{mM}$ during the 12,30 , and 240 $\mathrm{mU} / \mathrm{m}^{2} \cdot \mathrm{min}$ infusions. Only the plasma lactate concentration during the $240-\mathrm{mU} / \mathrm{m}^{2} \cdot \mathrm{min}$ infusion was significantly different from the basal value $(P<0.05)$. Lactate concentrations represent the mean over the last 30 min of each period.

In the five individuals who underwent a $240-\mathrm{mU} / \mathrm{m}^{2} \cdot \mathrm{min}$ insulin infusion to achieve maximal rates of glucose disposal,

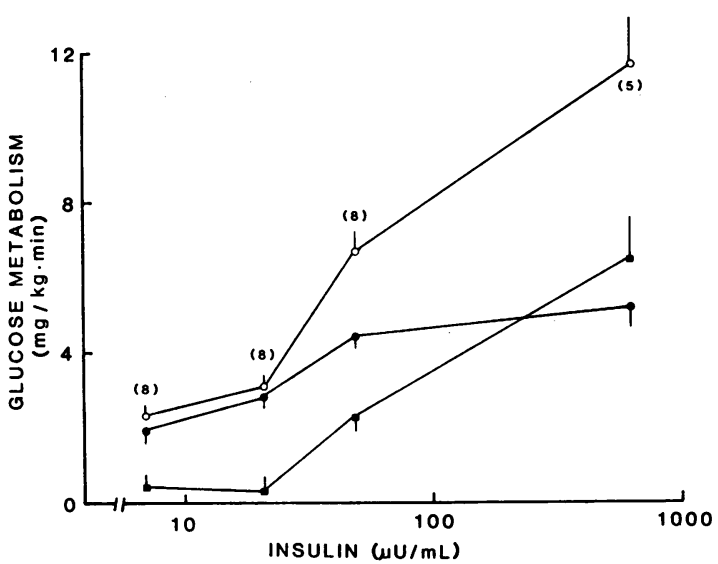

Figure 2. Effects of insulin infusion on glucose disposal rates (open circles) and rates of oxidative (solid circles) and nonoxidative (solid squares) glucose metabolism. Glucose disposal and oxidation rates were increased significantly $(P<0.001)$ over basal values at all insulin infusion rates. Nonoxidative glucose metabolism was increased significantly $(P<0.001)$ during the 30 - and $240-\mathrm{mU} / \mathrm{m}^{2} \cdot \mathrm{min}$ insulin infusions only.

it was also possible to calculate an $\mathrm{EC}_{50}$ for the effects of insulin. These $\mathrm{EC}_{50}$ 's should be regarded as approximate because of the limited nature of a four point dose-response curve. $\mathbf{E C}_{50}$ calculation may be performed with or without subtracting an estimate of the noninsulin-mediated portion of the measurement with which one is dealing. To accurately determine an $\mathrm{EC}_{50}$ for the effect of insulin, it is necessary to subtract any noninsulin-mediated component from each measurement. However, determination of this component is often difficult from both a theoretical and practical viewpoint. For purposes of illustration, the $\mathrm{EC}_{50}$ was calculated both ways for each process. For glucose disposal, a value of 0.75 times the basal glucose disposal rate was subtracted from each measurement of glucose disposal at each insulin level for each subject (40, 41). Felber et al. (42), reported that under conditions of somatostatin-induced insulinopenia, the entire decrease in basal disposal could be accounted for by decreased oxidation. Thus, noninsulin-mediated glucose oxidation was taken to be equal to the basal glucose oxidation rate minus 0.25 times the basal glucose disposal rate (the percentage decrease in basal glucose disposal seen during insulinopenia (40-42). For nonoxidative glucose metabolism, the value subtracted for each individual was equal to the difference between the estimate of the individual's rate of noninsulin-mediated glucose disposal and the es-

Table II. Effects of Insulin Infusion on Glucose Metabolism

\begin{tabular}{|c|c|c|c|c|}
\hline & \multicolumn{4}{|c|}{ Insulin infusion rate $\left(\mathrm{mU} / \mathrm{m}^{2} \cdot \mathrm{min}\right)$} \\
\hline & Basal & 12 & 30 & 240 \\
\hline Serum insulin, $\mu U / m l$ & $7 \pm 1$ & $22 \pm 2$ & $49 \pm 3$ & $631 \pm 49$ \\
\hline Glucose disposal* & $2.37 \pm 0.11$ & $3.15 \pm 0.19^{\ddagger}$ & $6.71 \pm 0.44^{\ddagger}$ & $11.7 \pm 1.73^{\ddagger}$ \\
\hline Glucose oxidation* & $1.96 \pm 0.18$ & $2.81 \pm 0.28^{\ddagger}$ & $4.43 \pm 0.32^{\ddagger}$ & $5.22 \pm 0.52^{\ddagger}$ \\
\hline Nonoxidative glucose metabolism* & $0.39 \pm 0.13$ & $0.34 \pm 0.26$ & $2.28 \pm 0.40^{\ddagger}$ & $6.52 \pm 1.21^{\ddagger}$ \\
\hline
\end{tabular}

*All rates are given in units of $\mathrm{mg} / \mathrm{kg} \cdot \min .{ }^{\ddagger}$ Greater than basal values, $P<0.01$, repeated measures analysis of variance. 
timate of noninsulin-mediated glucose oxidation. When these values were subtracted, the $\mathrm{EC}_{50}$ 's obtained were $65 \pm 16,28 \pm 6$, and $109 \pm 13$ for glucose disposal, oxidative, and nonoxidative glucose metabolism, respectively. Without subtracting noninsulin-mediated components, the $\mathrm{EC}_{50}$ 's for overall glucose disposal, oxidative, nonoxidative metabolism of glucose metabolism of glucose were $48 \pm 13,22 \pm 6$, and $97 \pm 17 \mu \mathrm{U} / \mathrm{ml}$. In either case, the $\mathrm{EC}_{50}$ for nonoxidative metabolism was significantly higher $(P<0.01)$ than that for glucose oxidation. Without attempting to correct for noninsulin-mediated rates, the $\mathrm{EC}_{50}$ for glucose disposal was significantly greater than that for glucose oxidation $(P<0.05)$ and significantly less than that for nonoxidative metabolism $(P<0.01)$. However, when noninsulin-mediated values were subtracted from glucose disposal and glucose oxidation, the $\mathrm{EC}_{50}$ for glucose disposal was not significantly different from the $\mathrm{EC}_{50}$ for either nonoxidative or oxidative glucose metabolism.

In vivo fat metabolism. The effects of insulin on plasmafree fatty acids (FFA) and fat oxidation are given in Table III. Basal rates of FFA and fat oxidation were suppressed by $70-80 \%$ at an insulin level of $20-25 \mu \mathrm{U} / \mathrm{ml}$ and were essentially completely suppressed at insulin concentrations $>50$ $\mu \mathrm{U} / \mathrm{ml}$. Negative fat oxidation rates achieved during the highest insulin infusion indicate that the RER slightly exceeded 1.0 and may represent lipogenesis (26).

In the five individuals who received a $240 \mu \mathrm{U} / \mathrm{M}^{2} \cdot \min$ insulin infusion, the $\mathrm{EC}_{50}$ for suppression of plasma FFA was $34 \pm 18 \mu \mathrm{U} / \mathrm{ml}$, while the $\mathrm{EC}_{50}$ for the suppressive effect of insulin on fat oxidation was $24 \pm 6 \mu \mathrm{U} / \mathrm{ml}$. This was based on suppression achieved during the $240 \mu \mathrm{U} / \mathrm{M}^{2} \cdot \min$ insulin infusion. The $\mathrm{EC}_{50}$ for suppression of fat oxidation by insulin was correlated with the $\mathrm{EC}_{50}$ for glucose oxidation $(r=0.95, P$ $<0.01)$ and glucose disposal $(r=0.67, P<0.05)$, but not nonoxidative glucose metabolism ( $r=0.43$, NS). When noninsulin-mediated rates were subtracted from glucose oxidation, the $\mathrm{EC}_{50}$ for fat oxidation was correlated with the $\mathrm{EC}_{50}$ for glucose oxidation $(r=0.93, P<0.01)$, but not for glucose disposal $(r=0.31, \mathrm{NS})$ or nonoxidative glucose metabolism ( $r$ $=0.08, \mathrm{NS})$.

$P D H$ activity. The kinetics of $\mathrm{PDH}_{\mathrm{a}}$ activity and total $\mathrm{PDH}$ activity $\left(\mathrm{PDH}_{\mathrm{t}}\right)$ in biopsies taken under basal and insulin-stimulated conditions are given in Table IV, and the effects of insulin infusion on the ratio $\mathrm{PDH}_{\mathrm{a}} / \mathrm{PDH}_{\mathrm{t}}$ are shown in Fig. 3 . Insulin infusion activated $\mathrm{PDH}_{\mathrm{a}}$ by increasing the $V_{\max }$, while the $K_{\mathrm{m}}$ was unaltered during the $12-$ and $30-\mathrm{mU} / \mathrm{m}^{2} \cdot \min$ infusions. $\mathrm{PDH}_{\mathrm{t}}$ was unchanged by insulin infusion. Consequently, the $\mathrm{PDH}$ activity ratio $\mathrm{PDH}_{\mathrm{a}} / \mathrm{PDH}_{\mathrm{t}}$ (Fig. 2) increased from $0.557 \pm 0.74$ basally to $0.635 \pm 0.093$ and $0.809 \pm 0.063$ at the $12-$ and $30-\mathrm{mU} / \mathrm{m}^{2} \cdot \min$ infusions, respectively $(P<0.05$, repeated measures analysis of variance). During the $240-\mathrm{mU} /$ $\mathrm{m}^{2} \cdot \mathrm{min}$ infusion, the activity ratio was $0.852 \pm 0.089$ in five individuals. For each of eight individuals considered under basal conditions and at the $12-$ and $30-\mathrm{mU} / \mathrm{m}^{2} \cdot \mathrm{min}$ insulin infusion, the activation of PDH by insulin was correlated with the activation of glucose oxidation on an individual basis (mean $r=0.68 \pm 0.17, P<0.01$ ). Additionally, the PDH activity ratio was negatively correlated with fat oxidation (mean $r$ $=-0.68 \pm 0.18, P<0.01)$. These correlation coefficients represent the means of correlation coefficients calculated for each individual. The mean coefficients were tested to determine whether they were statistically significantly different from zero.

GS activity. The effects of insulin on GS kinetics are given in Table $V$, and the effects of insulin infusion on the ratio of GS activity determined at $0.1 \mathrm{mM} \mathrm{G6P}$ to the activity of GS determined at $10 \mathrm{mM}$ G6P ( $F V_{0.1}$ or GS activity ratio) are shown in Fig. 3. Since a previous study (33) reported a Hill coefficient $>1.0$ for G6P for GS in human skeletal muscle, GS activities were fitted to the Hill equation. However, in this study the Hill coefficient was not found to be significantly different from 1.0. In contrast to $\mathrm{PDH}$, the major effect of insulin infusion was to activate GS by decreasing the $A_{0.5}$ for the allosteric activator G6P, while the $V_{\max }$ was unchanged at the $12-$ and $30-\mathrm{mU} / \mathrm{m}^{2} \cdot \mathrm{min}$ infusion. Total GS activity determined at maximal G6P and UDPG concentrations was also unchanged from basal values by the $12-$ and $30-\mathrm{mU} / \mathrm{m}^{2} \cdot \mathrm{min}$ infusions. However, both the $V_{\max }$ determined at low UDPG concentrations and total GS activity determined at maximally effective concentrations of both G6P and UDPG were significantly increased during the $240-\mathrm{mU} / \mathrm{m}^{2} \cdot \mathrm{min}$ infusion. The ratio of GS activity determined at $0.1 \mathrm{mM}$ G6P to that determined at $10 \mathrm{mM}$ G6P (the fractional velocity or $F V_{0.1}$ ) is thought to sensitively reflect dephosphorylation and activation of the enzyme. These ratios (Fig. 3) were $0.174 \pm 0.20$ basally and increased to $0.273 \pm 0.29,0.347 \pm 0.016$, and $0.545 \pm 0.031$ at the $12-, 30-$, and $240-\mathrm{mU} / \mathrm{m}^{2} \cdot \mathrm{min}$ insulin infusion, respectively. If it is assumed that the maximal value for the $F V_{0.1}$ is 1.0, it is possible to calculate an $\mathrm{EC}_{50}$ for the effect of insulin to activate GS. In the five individuals who underwent a 240 $\mathrm{mU} / \mathrm{m}^{2} \cdot \mathrm{min}$ infusion, the $\mathrm{EC}_{50}$ was $393 \pm 108 \mu \mathrm{U} / \mathrm{ml}$. If an $F V_{0.1}$ of 1.0 cannot in fact be achieved, the $\mathrm{EC}_{50}$ may be much lower than this value. From the present data, it is not possible to determine whether maximal $F V_{0.1}$ stimulation was achieved during the $240-\mathrm{mU} / \mathrm{m}^{2} \cdot \mathrm{min}$ insulin infusion. The relationship between the increase in $F V_{0.1}$ and activation of nonoxidative glucose metabolism was also determined in the same manner as for glucose oxidation and $\mathrm{PDH}$. Considering each of eight subjects examined through the $30 \mathrm{mU} / \mathrm{m}^{2} \cdot \mathrm{min}$ insulin infusion, the activation of GS was correlated with the activation of nonoxidative glucose metabolism (mean $r$ $=0.75 \pm 0.05$, significantly different from $0, P<0.01$ ).

PFK activity. In contrast to the effect of insulin to activate

Table III. Effects of Insulin Infusion on Fat Metabolism

\begin{tabular}{llccc}
\hline & \multicolumn{2}{l}{ Insulin infusion rate $\left(\mathrm{mU} / \mathrm{m}^{2} \cdot \min \right)$} & 30 & 240 \\
\cline { 2 - 5 } & Basal & 12 & $0.095 \pm 0.028^{*}$ & $0.060 \pm 0.030^{*}$ \\
Plasma free fatty acids, $\mathrm{mM}$ & $0.479 \pm 0.081$ & $0.151 \pm 0.036^{*}$ & $0.16 \pm 0.17^{*}$ & $-0.40 \pm 0.18^{*}$ \\
Fat oxidation, $\mathrm{mg} / \mathrm{kg} \cdot \mathrm{min}$ & $0.760 \pm 0.11$ & $0.19 \pm 0.16^{*}$ & & \\
\hline
\end{tabular}

* Less than basal, $P<0.001$, repeated measures analysis of variance. 


\begin{tabular}{|c|c|c|c|c|}
\hline & \multicolumn{4}{|c|}{ Insulin infusion rate $\left(\mathrm{mU} / \mathrm{m}^{2} \cdot \mathrm{min}\right)$} \\
\hline & Basal & 12 & 30 & 240 \\
\hline$K_{\mathrm{m}}, m M$ & $0.44 \pm 0.099$ & $0.40 \pm 0.06$ & $0.47 \pm 0.057$ & ND \\
\hline$V_{\max }, \mathrm{nmol} / \mathrm{min} \cdot \mathrm{mg}$ & $2.04 \pm 0.69$ & $1.95 \pm 0.59$ & $2.92 \pm 0.81^{*}$ & $3.79 \pm 1.99^{*}$ \\
\hline $\mathrm{PDH}_{\mathrm{t}}, \mathrm{nmol} / \mathrm{min} \cdot \mathrm{mg}$ & $3.56 \pm 0.94$ & $3.45 \pm 0.89$ & $3.38 \pm 0.80$ & $3.10 \pm 1.08$ \\
\hline
\end{tabular}

* Greater than basal, $P<0.01$, repeated measures analysis of variance.

PDH and GS, insulin infusion had no effect on PFK activity (Table VI). The $K_{\mathrm{m}}$ for F6P was $0.15 \pm 0.021 \mathrm{mM}$ under basal conditions and was unaltered by insulin. Likewise, the $V_{\max }$ of $0.16 \pm 0.019 \mathrm{nmol} / \mathrm{min} \cdot \mathrm{mg}$ under basal conditions was unaltered during infusion of insulin.

\section{Discussion}

The present studies were undertaken to determine the doseresponse relationships between insulin activation of oxidative and nonoxidative glucose metabolism in normal man with simultaneous measurement of the skeletal muscle enzymes that may control the rates of flux in these respective pathways. These studies confirm the findings of other investigators that oxidative glucose metabolism is more sensitive to insulin than nonoxidative metabolism based on $\mathrm{EC}_{50}$ values (2). This finding was apparent both with and without subtraction of estimates of noninsulin-mediated components of these processes. Since total glucose disposal is a function of both oxidative and nonoxidative metabolism, the sensitivity of glucose disposal to insulin necessarily lies between the insulin sensitivities of these processes. Nevertheless, at concentrations of insulin below 25 $\mu \mathrm{U} / \mathrm{ml}$, the majority of glucose disposal was accounted for by oxidative metabolism. Even at an insulin concentration of 50 $\mu \mathrm{U} / \mathrm{ml}$, almost $70 \%$ of glucose disposal was due to glucose oxidation. Thus, at physiologic insulin concentrations $(<50$ $\mu \mathrm{U} / \mathrm{ml}$ ) in normal man, the stimulation of glucose oxidation by insulin accounted for the majority of glucose disposal. In keeping with this observed effect of insulin on glucose oxidation, muscle PDH activity was $>50 \%$ active at basal insulin concentrations and was almost fully active at an insulin concentration of $50 \mu \mathrm{U} / \mathrm{ml}$. In fact, the activation of PDH by insulin was correlated with the activation of glucose oxidation over the physiologic range of insulin concentrations. This sug-

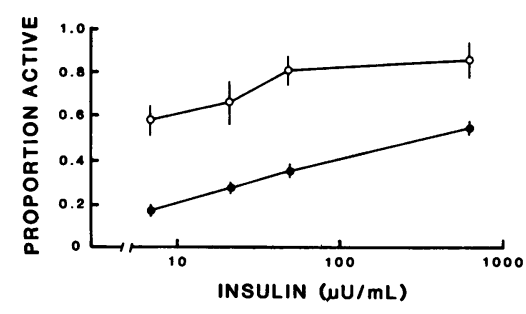

Figure 3. Effects of insulin infusion on PDH (open circles) and GS (solid circles). For PDH, the proportion active was calculated as the ratio $\mathrm{PDH}_{\mathrm{a}} / \mathrm{PDH}_{\mathrm{t}}$, while for GS the proportion active was cal-

culated as the ratio of GS activity determined at $0.1 \mathrm{mM}$ G6P to the activity of $10 \mathrm{mM}$ G6P (see text for details). GS was significantly activated at all insulin infusions $(P<0.001)$. PDH was significantly activated at the $30-$ and $240-\mathrm{mU} / \mathrm{m}^{2} \cdot \mathrm{min}$ infusions $(P<0.01)$. gests that PDH in skeletal muscle plays an important role in determining the rate of insulin-stimulated glucose oxidation by the whole body. Since glucose oxidation nearly quantitatively accounts for overall rates of glucose disposal at low insulin concentrations, it is also possible that PDH may be significant in determining the rate of glucose disposal at physiologic insulin concentrations. It should be noted that a wide range of values for basal glucose oxidation has been reported (1-3), including some that are lower than those observed in the present study. These differences may reflect differences in the nutritional state of the subjects or the type of indirect calorimeter employed. Nevertheless, the pattern of insulin stimulation of glucose oxidation in all studies is nearly identical to that reported in the present results.

In contrast, nonoxidative metabolism of glucose, which is thought to primarily represent glycogen synthesis, accounted for only a majority of overall glucose disposal at insulin concentrations $<25 \mu \mathrm{U} / \mathrm{ml}$. Consistent with the fact that under basal, postabsorptive conditions, there is probably little net glycogen synthesis in skeletal muscle, the basal rates of nonoxidative glucose metabolism, observed in this study were negligible, and may primarily represent other processes such as lactate production from glucose. Therefore, at insulin concentrations $<25 \mu \mathrm{U} / \mathrm{ml}$, there appeared to be little net glucose storage. At somewhat higher insulin concentrations $(\sim 50$ $\mu \mathrm{U} / \mathrm{ml}$ ) such as those which might be achieved following a meal, there was significant nonoxidative glucose metabolism. In addition, postprandial hyperglycemia should further augment nonoxidative glucose metabolism compared to the present study in which glucose levels were held constant.

The present studies confirm the findings of others (6-9) that infusion of insulin and glucose activates skeletal muscle GS and extend these findings by demonstrating that muscle GS is significantly activated in normal subjects over the physiologic range of insulin concentrations. For example, an insulin concentration of $15-25 \mu \mathrm{U} / \mathrm{ml}$ achieved during the $12-\mathrm{mU} /$ $\mathrm{m}^{2} \cdot \mathrm{min}$ insulin infusion activated GS in seven out of eight subjects. This observation demonstrates that GS is activated even at low insulin concentrations. Unfortunately, since it is unknown whether maximal activation of GS was achieved during the $240-\mathrm{mU} / \mathrm{m}^{2} \cdot \mathrm{min}$ insulin infusion, it was not possible to precisely calculate an $\mathrm{EC}_{50}$ for insulin stimulation of this process from this data. However, it would seem that the sensitivity of GS to insulin may be similar to that of overall nonoxidative glucose metabolism. This would be consistent with a regulatory role for skeletal muscle GS in the activation of nonoxidative glucose metabolism by insulin.

However, there was an apparent discrepancy between the stimulation of GS by insulin and the stimulation of nonoxida- 


\begin{tabular}{lccccc}
\hline & \multicolumn{2}{l}{ Insulin infusion rate $\left(\mathrm{mU} / \mathrm{m}^{2} \cdot \min \right)$} & & \\
\cline { 2 - 5 } & Basal & 12 & 30 & 240 \\
\hline$V_{\max }, \mathrm{nmol} / \mathrm{min} \mathrm{mg}$ & $12.0 \pm 2.59$ & $11.90 \pm 2.34$ & $14.40 \pm 2.18$ & $17.30 \pm 0.92^{*}$ \\
G6P $A_{0.5}, \mathrm{mM}$ & $0.64 \pm 0.07$ & $0.43 \pm 0.07^{\ddagger}$ & $0.32 \pm 0.04^{\ddagger}$ & $0.13 \pm 0.005^{\ddagger}$ \\
Hill coefficient & $1.0 \pm 0.05$ & $1.0 \pm 0.04$ & $0.92 \pm 0.03$ & $1.09 \pm 0.08$ \\
Maximal activity, $\mathrm{nmol} / \mathrm{min} \mathrm{mg}$ & $20.3 \pm 5.5$ & $19.4 \pm 5.2$ & $25.9 \pm 3.89$ & $28.6 \pm 0.52^{*}$ \\
\end{tabular}

* Greater than basal, $P<0.001$, repeated measures analysis of variance. Maximal activity represents enzyme activity in the presence of $10 \mathrm{mM}$ G6P and $5 \mathrm{mM}$ UDPG, while $V_{\max }$ is determined at $10 \mathrm{mM} \mathrm{G6P}$ and $0.3 \mathrm{mM}$ UDPG. ${ }^{\ddagger}$ Less than basal $A_{0.5}, P<0.001$, repeated measures analysis of variance.

tive glucose metabolism by insulin. When the mean plasma insulin was increased to $22 \pm 2 \mu \mathrm{U} / \mathrm{ml}$, the mean rate of nonoxidative glucose metabolism did not increase. Yet, the mean activity of muscle GS was increased by nearly twofold. Several hypotheses can be entertained to explain this discrepancy. First, it is possible that at insulin concentrations $<25 \mu \mathrm{U} / \mathrm{ml}$, glycogen synthase activity does not determine the rate of glucose incorporation into glycogen in skeletal muscle. Second, although the rate of nonoxidative glucose metabolism did not increase, it is possible that the component of this overall process due to glycogen synthesis was increased, while some other component of nonoxidative glucose metabolism (such as lactate production from glucose) was decreased, resulting in no net change in the overall process. Third, it is possible that a small insulin-induced decrease in muscle G6P concentration brought about by activation of glycolysis or glucose oxidation may have compensated for the insulin-induced activation of glycogen synthase, resulting in no net in vivo increase in enzyme activity. It is not possible to distinguish among these possibilities from the present data.

Nevertheless, at insulin concentrations $<50 \mu \mathrm{U} / \mathrm{ml}$, the glycogen synthase $F V_{0.1}$ was positively correlated with the rate of net nonoxidative glucose metabolism in normal man ( $r$ $=0.75 \pm 0.05, P<0.01$ ), suggesting that this enzyme may be rate-determining for glucose storage under physiologic conditions. When plasma insulin was increased to values greater than the physiologic range, muscle glycogen synthase activity seemed to be even more important in determining the rate of nonoxidative glucose metabolism. In the five individuals who underwent additional insulin infusions at $240 \mathrm{mU} / \mathrm{m}^{2} \mathrm{~min}$, the $F V_{0.1}$ was highly correlated on an individual basis with nonoxidative metabolism (mean $r=0.91 \pm 0.005, P<0.01$ ).

The effects of insulin on fat metabolism were also examined in the current studies. Insulin suppressed both fat oxidation and plasma FFA concentrations similarly. In addition, the sensitivity of suppression of fat oxidation by insulin was quite similar to the sensitivity of activation of glucose oxidation by insulin. In fact, the $\mathrm{EC}_{50}$ for suppression of fat oxidation was highly correlated with the $\mathrm{EC}_{50}$ for activation of glucose oxidation $(r=0.95, P<0.01)$. In theory, this may be due to the suppressive effects of the fat oxidation products citrate and acetyl-CoA on PFK and PDH activity $(11-13,16,17)$. However, the use of respiratory exchange measurements for determining the proportions of glucose and fat oxidized requires the use of the same measurements of $\mathrm{CO}_{2}$ production and $\mathrm{O}_{2}$ consumption to calculate both glucose and fat oxidation. Therefore, the high correlation between glucose and fat oxidation may merely be an artefact of the method used to measure them. To truly determine the association between these two variables, independent measurements of glucose and fat oxidation would need to be made.

These studies also demonstrate that insulin infusion activates PDH in skeletal muscle in normal man. Similar to the exquisite sensitivity to insulin of whole-body glucose oxidation, PDH was nearly maximally activated by insulin concentrations of $40-60 \mu \mathrm{U} / \mathrm{ml}$. Thus, maximal activation of glucose oxidation occurs at insulin concentrations similar to those that produce maximal activation of PDH. This suggests, but does not prove, that msucle $\mathrm{PDH}$ is rate- determining for glucose oxidation under conditions of insulin infusion in man. Approximately half of the PDH in muscle in the basal state was present in its active form, compared to only $15-20 \%$ of total GS. Since the majority of glucose disposal in the basal state was accounted for by glucose oxidation, and only a small portion was due to nonoxidative metabolism, one could conclude that the relative activation states of GS and PDH make significant contributions to the control of the routes of glucose metabolism. However, since only a minority of glucose disposal under basal conditions occurs in muscle (1), conclusions concerning the role of GS or PDH in basal glucose metabolism

Table VI. Effects of Insulin on PFK Kinetics

\begin{tabular}{lllll}
\hline & \multicolumn{2}{l}{ Insulin infusion rate $\left(\mathrm{mU} / \mathrm{m}^{2} \cdot \mathrm{min}\right)$} & & 240 \\
\cline { 2 - 5 } & Basal & 12 & $0.176 \pm 0.021$ & $0.15 \pm 0.031$ \\
$V_{\max }, \mathrm{nmol} / \mathrm{min} \cdot \mathrm{mg}$ & $0.161 \pm 0.19$ & $0.17 \pm 0.017$ & $0.153 \pm 0.015$ & ND \\
$K_{\mathrm{m}}, \mathrm{mM}$ & $0.150 \pm 0.021$ & $0.137 \pm 0.013$ & & \\
\hline
\end{tabular}


which are based on activities of these enzymes in skeletal muscle must be viewed cautiously. This caveat is less applicable under conditions of insulin infusion in which the majority of glucose disposal occurs in muscle.

The current studies provide no evidence for a role of insulin in activating the glycolytic pathway by means other than increasing substrate availability, since PFK activity was unchanged at any insulin concentration. While this demonstrates that insulin did not cause covalent modification of skeletal muscle PFK, which altered its activity, the enzyme might have been activated allosterically in vivo if intracellular citrate concentrations were decreased. Since intracellular citrate levels were not measured, it is not possible to address this question.

In summary, the current studies provide evidence that skeletal muscle PDH and GS may in part determine the rates of insulin-stimulated glucose oxidation and storage in normal subjects. The findings of these studies may also have implications concerning the mechanisms of skeletal muscle insulin resistance in obesity or diabetes mellitus, conditions that are characterized by defects in both oxidative and nonoxidative metabolism of glucose, which could reflect abnormalities in the regulation of PDH and GS, respectively. Additional studies will be required to clarify this issue.

\section{Acknowledgments}

Thanks are due to R. Thorne, P. Elliott, E. Martin, and T. Morrison for excellent technical assistance, the nursing staff of the General Clinical Research Center, and C. Knowles for excellent editorial assistance.

This study was supported in part by a grant to $L$. Mandarino from the American Diabetes Association, Southern California Affiliate; NOVO Research Institute, Copenhagen; and General Clinical Research Center grant RR00827.

\section{References}

1. De Fronzo, R. A., E. Jacot, E. Jequier, E. Maeder, J. Wahren, and J. P. Felber. 1981. The effect of insulin on the disposal of intravenous glucose. Results from indirect calorimetry and hepatic and femoral venous catheterization. Diabetes. 30:1000-1007.

2. Thiebaud, D., E. Jacot, R. A. De Fronzo, E. Maeder, E. Jequier, and J. P. Felber. 1982. The effect of graded doses of insulin on total glucose uptake, glucose oxidation, and glucose storage in man. Diabetes. 31:957-963.

3. Bogardus, C., S. Lillioja, K. Stone, and D. Mott. 1984. Correlation between muscle glycogen synthase activity and in vivo insulin action in man. J. Clin. Invest. 73:1185-1190.

4. Rosell-Perez, M., C. Villar-Palasci, and J. Larner. 1962. Studies on UDPG-glycogen transglucosylase. I. Preparation and differentiation of two activities of UDPG-glycogen transglucosylase from rat skeletal muscle. Biochemistry. 1:763-768.

5. Friedman, D. L., and J. Larner. 1963. Studies on UDPG- $\beta$-glucan transglucosylase. III. Interconversion of two forms of muscle UDPG- $\beta$-glucan transglucosylase by a phosphorylation-dephosphorylation reaction sequence. Biochemistry. 2:669-675.

6. Roch-Norlund, A. E., J. Bergstrom, and E. Hultman. 1972. Muscle glycogen and glycogen synthase in normal subjects and in patients with diabetes mellitus. Effect of intravenous glucose and insulin administration. Scand. J. Clin. Lab. Invest. 30:77-84.

7. Nuttall, F. Q., J. Barbosa, and M. C. Gannon. 1974. The glycogen synthase system in skeletal muscle of normal humans and patients with myotonic dystrophy. Effect of glucose and insulin administration. Metab. Clin. Exp. 23:561-568.

8. Evans, D. J., R. Murray, and A. H. Kissebah. 1984. Relationship between skeletal muscle insulin resistance, insulin-mediated glucose disposal, and insulin binding. Effects of obesity and body fat topography. J. Clin. Invest. 74:1515-1525.

9. Devlin, J. T., and E. S. Horton. 1985. Effects of prior high-intensity exercise on glucose metabolism in normal and insulin-resistant men. Diabetes. 34:973-979.

10. Randle, P. J., E. A. Newsholme, and P. B. Garland. 1964. Regulation of glucose uptake by muscle. 8 . Effects of fatty acids, ketone bodies and pyruvate, and of alloxan diabetes and starvation, on the uptake and metabolic fate of glucose in the rat heart and diaphragm muscles. Biochem. J. 93:652-665.

11. Garland, P. B., E. A. Newsholme, and P. J. Randle. 1964 Regulation of glucose uptake by muscle. 9 . Effects of fatty acids and ketone bodies, and of alloxan diabetes and starvation, on pyruvate metabolism and on lactate/pyruvate and L-glycerol 3-phosphate/dihydroxyacetone phosphate concentration ratios in rat heart and diaphragm muscles. Biochem. J. 93:665-678.

12. Garland, P. B., and P. J. Randle. 1964. Regulation of glucose uptake by muscle. 10. Effects of alloxan-diabetes, starvation, hypophysectomy and adrenalectomy, and of fatty acids, ketone bodies and pyruvate on the glycerol output and concentrations of free fatty acids, long-chain fatty acyl-coenzyme A, glycerol phosphate and citrate cycle intermediates in rat heart and diaphragm muscles. Biochem. $J$. 93:678-687.

13. Randle, P. J., P. B. Garland, C. N. Hales, and E. A. Newsholme. 1963. The glucose fatty-acid cycle. Its role in insulin sensitivity and the metabolic disturbances of diabetes mellitus. Lancet. i:7285-7289.

14. Weiss, L., G. Loffler, A. Schirmann, and O. H. Wieland. 1971. Control of pyruvate dehydrogenase interconversion in adipose tissue by insulin. FEBS (Fed. Eur. Biochem. Soc.) Lett. 15:229-231.

15. Mandarino, L. J., Z. Madar, O. G. Kolterman, J. M. Bell, and J. M. Olefsky. 1986. Adipocyte glycogen synthase and pyruvate dehydrogenase in obese and type II diabetic subjects. Am. J. Physiol. 251(Endocrinol. Metab. 14):E489-E496.

16. Denton, R. M., P. J. Randle, B. J. Bridges, R. H. Cooper, A. L. Kerbey, T. H. Pask, D. L. Severson, D. Stansbie, and S. Whitehouse. 1975. Regulation of mammalian pyruvate dehydrogenase. Mol. Cell. Biochem. 9:27-53.

17. Wieland, O. H. 1983. The mammalian pyruvate dehydrogenase complex. Structure and regulation. Rev. Physiol. Biochem. Pharmacol. 96:124-146.

18. Kolterman, O. G., S. R. Gray, J. Griffin, P. Burstein, J. Insel, J. A. Scarlett, and J. N. Olefsky. 1981. Receptor and postreceptor defects contribute to the insulin resistance in noninsulin-dependent diabetes mellitus. J. Clin. Invest. 68:957-969.

19. Kolterman, O. G., J. Insel, M. Saekow, and J. M. Olefsky. 1980. Mechanisms of insulin resistance in human obesity. J. Clin. Invest. 65:1272-1284.

20. Bolinder, J., J. Ostman, and P. Arner. 1982. Postreceptor defects causing insulin resistance in normoinsulinemic noninsulin-dependent diabetes mellitus. Diabetes. 31:911-916.

21. Lonnrath, P., M. DiGiralamo, M. Krotkiewski, and U. Smith. 1983. Insulin binding and responsiveness in fat cells from patients with reduced glucose tolerance and type II diabetes. Diabetes. 32:748-754.

22. Pedersen, O., E. Hjollund, and S. Schwartz. 1982. Insulin receptor binding and insulin action in human fat cells: Effects of obesity and fasting. Metab. Clin. Exp. 31:884-895.

23. Ciaraldi, T., O. Kolterman, J. Scarlett, M. Kao, and J. Okefsky. 1982. Role of glucose transport in the postreceptor defect of non-insulin-dependent diabetes mellitus. Diabetes. 31:1016-1022.

24. Boden, G., T. K. Ray, R. H. Smith, and O. E. Owen. 1983. Carbohydrate oxidation and storage in obese non-insulin-dependent diabetic patients. Diabetes. 32:982-987.

25. National Diabetes Data Group. 1979. Classification and diagnosis of diabetes mellitus and other categories of glucose intolerance. Diabetes. 28:1039-1057.

26. Frayn, K. N. 1983. Calculation of substrate oxidation rates in vivo from gaseous exchange. J. Appl. Physiol. (Respir. Environ. Exercise Physiol.) 55:628-634. 
27. Steele, R., J. Wall, R. DeBodo, and N. Altszuler. 1956. Measurement of size and turnover rate of body glucose pool by the isotope dilution method. Am. J. Physiol. 187:15-24.

28. Bergstrom, J. 1962. Muscle electrolytes in man. Determined by neutron activation analysis on needle biopsy specimen. A study on normal subjects, kidney patients, and patients with chronic diarrhea. Scand. J. Clin. Lab. Invest. 14(Suppl. 68):1-110.

29. Hagg, S. A., S. I. Taylor, and N. B. Ruderman. 1976. Glucose metabolism in perfused skeletal muscle. Pyruvate dehydrogenase activity in starvation, diabetes and exercise. Biochem. J. 158:203-210.

30. Lowry, O. H., N. J. Rosebrough, A. L. Farr, and R. J. Randall. 1951. Protein measurements with the Folin phenol reagent. J. Biol. Chem. 193:265-272.

31. Blass, J. P., J. Avigan, and B. W. Uhlendorf. 1970. A defect in pyruvate decarboxylase in a child with an intermittent movement disorder. J. Clin. Invest. 49:423-432.

32. Thomas, J., K. Schlender, and J. Larner. 1968. A rapid filter paper assay for UDP-glucose-glycogen glucosyltransferase, including an improved biosynthesis of UDP- ${ }^{14} \mathrm{C}$-glucose. Anal. Biochem. 25:486-499.

33. Kochan, R. G., D. R. Lamb, S. A. Lutz, C. V. Perrill, E. M. Reimann, and K. K. Schlender. 1979. Glycogen synthase activation in human skeletal muscle. Effects of diet and exercise. Am. J. Physiol. 5:E660-E666.

34. Kochan, R. G., D. R. Lamb, E. M. Reimann, and K. K. Schlender. 1981. Modified assays to detect activation of glycogen synthase following exercise. Am. J. Physiol. 240(Endocrinol. Metab. 3):E197-E202.

35. Kaslow, H. R., and R. D. Eichner. 1984. Fasting and diabetes alter adipose tissue glycogen synthase. Am. J. Physiol. 247(Endocrinol. Metab. 10):E581-E584.

36. Beutler, E. 1971. Phosphofructokinase. In Red cell metabolism: A manual of biochemical methods. E. Beutler, editor. Grune \& Stratton, Inc., New York. 42-44.

37. Itaya, K., and U. Michio. 1965. Colorimetric determination of free fatty acids in biological fluids. J. Lipid Res. 6:16-20.

38. Passoneau, J. V. 1974. L-(+)-lactate. Fluorometric method. In Methods of Enzymatic Analysis. H. V. Bergemeyer, editor. Academic Press, New York. 3:1468-1472.

39. Winer, B. J. 1971. Statistical Principles in Experimental Design. McGraw-Hill Book Co., New York.

40. Gottesman, I., L. Mandarino, C. Verdonk, R. Rizza, and J. Gerich. 1982. Insulin increases the maximal velocity for glucose uptake without altering the Michaelis-Menten constant in man. Evidence that insulin increases glucose uptake merely by providing additional transport sites. J. Clin. Invest. 70:1310-1314.

41. Baron, A. D., O. G. Kolterman, J. Bell, L. J. Mandarino, and J. M. Olefsky. 1985. Rates of noninsulin-mediated glucose uptake are elevated in type II diabetic subjects. J. Clin. Invest. 76:1782-1788.

42. Felber, J. P., D. Thiebaud, E. Maeder, E. Jequier, R. Hendler, and R. A. DeFronzo. 1983. Effect of somatostatin-induced insulinopenia on glucose oxidation in man. Diabetologia. 25:325-330. 